\section{Assessing the Interdependence between Organizational Culture and Performance in the Construction Industry}

\author{
Denbeshu Neare Jabo \\ Hawassa University, Hawassa, Ethiopia \\ denbeshun@hu.edu.et/denbe2010@gmail.com
}

Management,

Knowledge and Learning learn International Conference 2021

Technology, Innovation and Industrial Management

Economy for a New Normal: Digitalisation and Human Relations in Business and Education 20-21 May 2021 Online Conference

Purpose: This paper examines the interdependence between organizational culture and performance in the construction industry in developing countries. It explored how organizational culture and organizational performance are related to and influence one another thereby determining the success of the construction industry.

Study design/methodology/approach: The paper obtained data through the systematic review of literature on theories, models, and concepts of the interaction between organizational culture and performance. This comprehensive literature review also identified major dimensions of interaction between organizational culture and organizational performance, and how the interaction between the two influences the successes or the failure of the organization. The review also summarized the major theories and models on organizational culture and its interaction with organizational success in the construction industry. The outcome is identifying the relationship and trying to develop appropriate knowledge management-based improvement framework model for the construction industry organizational culture environment.

Findings: The findings of this literature review revealed that there is a direct relationship between organizational culture and performance. It also showed that there is a significant implication for future researches, and identified gaps to be fulfilled by the extended studies in the areas.

Originality/value: The findings increased the validity and the relevance of the competing values framework model in the construction industry organizational culture environment and future detail studies are proposed.

Keywords: Organizational culture, Interdependence, Organizational performance, Construction industry

\title{
INTRODUCTION
}

\section{The Concepts and Definitions}

Different researchers present the concept and definitions of organizational culture, it is the collective effect of the common beliefs, behaviour, and values of the people within a company ( Marcos, 2018). Organizational culture is a complex and deep aspect of organizations that can strongly affect organization members (Joseph, 2016). Organizational culture has many dimensions and variations (Skerlavaj et al., 2007). There are seven dimensions of organizational culture that emphasize different aspects of culture and suggest different ways to understand an organization's culture. The level dimension, pervasiveness dimension, implicitness dimension, imprinting dimension, political dimension, plurality dimension, and interdependency dimension, (Joseph,2016). Organizational culture is the basic philosophy of an organization that has beliefs, norms, and values as a guideline for all human resources in the organization in carrying out their activities in the work environment. Organizational culture can create characteristics that will become the identity of an organization (Rohman et al.,2021).

Organizational culture plays an important role in improving the effective performance of an organization. For organizations, culture is a benchmark for achieving organizational success while building a commitment to realizing the vision, winning the hearts of customers, winning the competition, and building company strength (Rohman et al., 2021). Organizational culture best supports business transformation. It is the customary and traditional way of doing things, 
which is shared to a greater or lesser degree by all members, and which the new members must learn and at least partially accept to be accepted for the firm's services (Skerlavaj et al., 2007). Organizational culture can specifically be determined by the conditions of teamwork, leadership, organizational characteristics, and applicable administrative processes. In its function, organizational culture is also an employee unifier, a reducer of conflict, and a motivator for employees to carry out their duties properly ( Rohman et al., 2021).

Performance is the process and the results of the efforts of individual and group organizations in a certain period. The abilities and talents possessed by each employee have different results, the success of an organization depends on the individual performance of each employee. An organization needs employees who have the talent and ability to complete their work (Rohman et al., 2021). Organizational performance refers to the nature and quality of an action performed in a company to achieve the accomplishment of its primary functions and tasks to produce a profit. To measuring organizational performance based on two factors (i.e., a good fit between the organization and its environments; and a good fit between the organization and its contributors) the concept of performance dealt with both organizational means and ends (Jenatabadi,2015). The performance of human beings in the organization is dependent on the ability embedded in motivation ( Matkó \&Takács, 2017).

Many researchers have identified the organizational culture and performance are positively interrelated. The key to good performance is a strong culture. A positive and strong culture can make an average individual perform and achieve brilliantly whereas a negative and weak culture may demotivate an outstanding employee to underperform and end up with no achievement. Organizational culture has an active and direct role in performance management (Ehtesham et al., 2011). In an organization there is a strong organizational culture with gratitude and recognition towards employees, this will cause the strengthening of motivation and significant performance improvements ( Matkó \& Takács,2017). Organizational culture has a positive effect on individual and organizational performance (Cheung et al.,2012).

In construction, compliance with predetermined criteria regarding time, cost, and quality are the key indicators typically used (Cheung et al., 2012). Organizational culture in the construction industry has unique characteristics. Specific characteristics of the construction industry include the following: geographically distributed nature of construction, dynamic nature of site management, highly mobile and itinerant workforce, the large number of organizations that have to work together in projects, and their perspective on time (Šandrk Nukić, 2018). The need for understanding and appreciating the culture has become even more important the projects are also subjected to dispute and misunderstanding risks among member firms, which in turn could cause potentially beneficial relationships to turn into relationships that more adversarial relationships in nature (Nifa \& Ahmed, 2010).

\section{Methodology}

In this Comprehensive literature review classical and contemporary papers published in the areas of organizational culture, organizational performance, and the relationship between organizational culture and performance are assessed. Also, the review included the published papers that related to the organizational culture of the construction industry organizational culture environment. The paper obtained data through the systematic review of literature on theories, models, and concepts of the interaction between organizational culture and performance. 


\section{Literature Review}

\section{Organizational culture}

Different researchers in the field of organizational culture tried to conceptualize and define the concept and definition of Organizational culture. There is not a generally accepted definition of organizational culture. Organizational culture is defined as a concept that orients employees, guides them in their behaviour and communication, and shows the character of the organization (Yildiz, 2019). Organizational culture encompasses a solid set of symbols and meanings shared by all organizational members, which generate consensus among them (Larentis et al., 2018). Organizational culture is the shared basic assumptions, values, and beliefs of the members of the organization. Organizational culture is the way that managers and employees solve problems in the organization (Tedla, 2016).

There have been two distinct approaches to the definition of culture. While the first approach treats organizational culture as something an organization is, the second one accepts culture as something an organization has. In the light of the functionalist approach, the development of organizational culture is related to the capability of organizations in solving their external adaptation and internal integration problems, and the development of culture is identical to the process of group formation (Yahyagil, 2004). It can be seen that organizational cultures at three different, but related, levels: artefacts, values, High visibility characteristics, and basic assumptions. These levels vary invisibility to an outsider (Joseph, 2017). The first is the easiest to see and the last is the most difficult. Organizational culture is composed of three levels as artefacts at the visible level, values (not observable) at the mid-level, and basic assumptions at the core of the formation (Yahyagil, 2004).

There are four characteristics of organizational culture, organizational culture is a learned or acquired phenomenon. Organizational culture should be shared by the group members. Organizational culture is not in the written text format. Organizational culture exists in the mindset, consciousness, and mind of the group members as beliefs and values. organizational culture reveals itself as steady repetitive or emerging behavioural patterns (Yildiz, 2019). Organizational culture is playing an indirect role in influencing behaviour by using reasonable managerial tools, such as strategic direction, goals, tasks, technology, structure, communication, decision making cooperation, and interpersonal relationships, and which are all designed to do things (Sun 2009). Specialists consider that organizational culture plays an important role in differentiating organizations from each other (Botez \& Cotet, 2020).

\section{Organizational Culture in the construction Industry}

The construction industry is not well appreciated until the late 1990s and early 2000s. There is no common definition, and there are even arguments about whether it is an industry or a sector that comprises many industries (Ofori, 2015). The construction industry is traditionally divided into three sub-sectors. They are; the construction of buildings, road, highway, and other infrastructure construction, and speciality trades. It is widely recognized that the construction industry has a positive role to accelerate the wheel of economic growth in any country (Dakhil, 2013). The construction industry has peculiar features that need to be appreciated if it is to be able to perform effectively and efficiently (Ofori, 2015). 
Understanding organizational culture is fundamental to examine what goes on in organizations, how to run them, and how to improve them (Oney-Yazici et al., 2007). Several organizational scholars and observers recognize that organizational culture has a powerful effect on the performance and long-term effectiveness of organizations, and what differentiates successful firms from others is their organizational culture (Oney-Yazici et al., 2007).

The literature revealed that there are different types of organizational culture models developed by organizational scholars. For this paper's purpose, the model developed by Cameron and Quinn, (2006) is assessing and discussed in detail to identify the relevance of the model in the construction industry organizational culture environment.

This model has been used in most largescale construction industries in developed and developing countries. The researchers argue that an organizational culture of the construction industry is planned for short, and medium terms, sometimes even for a long period, construction work is team-oriented, requires innovation, collaboration, and cooperation, adhocracy approach, teamwork, quality control, and competence and competition in different aspects, regarding this model the detail presented below.

An organization that is dominated by the clan culture attaches great importance to teamwork, participation, consensus, morale, and loyalty. Success is defined in terms of sensitivity to customers in clan culture-oriented organizations. Adhocracy culture encourages creativity, experimentation, innovation, and individual initiative. Gaining unique products and being a product leader are the criteria for being successful in organizations that are dominated by an adhocracy culture. Hierarchy culture leads to an organization that has formalized structure, formal rules, and policies. Success is defined in terms of dependable delivery and smooth scheduling in hierarchy culture-oriented organizations. Market culture focuses on getting the job done which brings goal-oriented competition along. Reputation and market leadership are the main concerns of success in market culture-oriented organizations (Arditi et al., 2017).

The literature revealed that this model is more appropriate, and using in most developed and developing countries' construction industry organizational culture environments, such as in Europe, Asia Australia, and Africa. Moreover, for this comprehensive literature review among several organizational culture models, one is selected to continue further research in the next phase and to propose the project to implement this model in the construction organizational culture environment.

The organizational culture assessment instrument developed by Cameron and Quinn (2006) is composed of four competing values that refer to four types of organizational culture: flexibility /internal focus clan culture, control internal focus hierarchy culture, flexibility /external focus adhocracy culture, and control /external focus market culture. This tool evaluates six dimensions of the organization: dominant characteristics, organizational leadership, employee management, organizational adhesive, strategic accents, and success criteria (Botez \& Cotet, 2020). 


\section{Flexibility and Discretion}

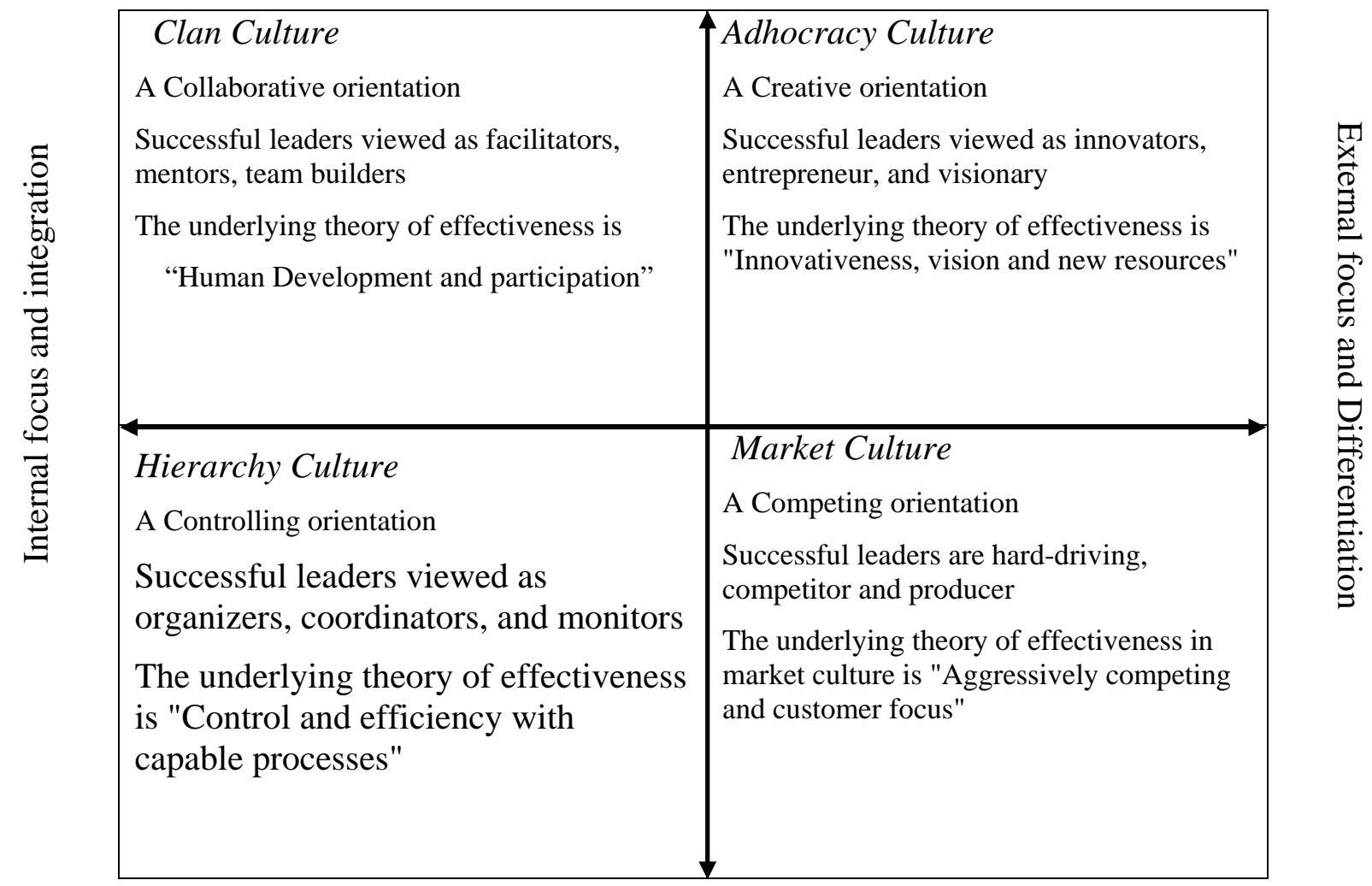

Stability and Control

Figure 1: Competing Values Framework, Model, adapted from (Cameron and Quinn,2006)

\section{Organizational Performance}

Organizational performance as a concept is defined with different variables in the literature financial variables or concepts from human resources management are used to assess the performance of organizations. Scholars often use the terminology organizational effectiveness and organizational performance interchangeably to describe the same phenomenon (Yildiz, 2014). It has been very important for managers to know which factors influence an organization's performance for them to take appropriate steps to initiate them. However, defining, conceptualizing, and measuring performance has not been an easy task. Researchers among themselves have different opinions and definitions of performance, which remains to be a contentious issue among organizational researchers (Kinoshita,2014).

Organizational performance is the organization's ability to attain its goals by using resources efficiently and effectively (Kinoshita,2014). Scholars use the terminology organizational effectiveness and organizational performance interchangeably to describe the same phenomena. The organizational performance seen in the other version that divided into two dimensions of employee performance the first dimension related to task performance or (technical job performance) is the behaviour associated with maintaining and serving an organization's 
technical core. The second dimension is the contextual performance dimension or (interpersonal job performance) is a function of one's interpersonal skill knowledge that supports the broader social environment in which the technical core must function (Ying\& Ahmed,2009). Performance is the process and the results of the efforts of individual and group organizations in a certain period, the abilities and talents possessed by each employee have different results, the success of an organization depends on the individual performance of each employee. An organization needs employees who have the talent and ability to complete their work (Teräväinen et al., 2018).

\section{The Relationship Between Organizational Culture and Performance}

The relationship between organizational culture and organizational performance has drawn the attention of researchers and become a popular subject matter (Alla \& Hassan,2017). Several studies have been devoted to examining the role of culture as an organizational resource or asset which affects performance (Projogo \& Dormott, 2011). A particular assumption about what culture is will influence its definition and the method used to assess it. These different definitions and methods of assessment will, in turn, lead to different findings of the relationship between culture and performance (Leity,2017).

There are four views on the relationship between organizational cultures and performance the most common one is the strong-culture thesis. It has often been assumed the commitment of an organization's employees and organizational culture and Performance. Managers to the same set of values, beliefs, and norms will have positive results that the strength of organizational culture is directly correlated with the level of profits in a company (Mousavi et al., 2015). The other common cultural view is motivating people to recognize their identity by the organization and have a sense of belonging and responsibility to the organization. Organizational culture should be harmonized to its environment, in a competitive environment, the relationship between cultural traits and effectiveness is moderated by them, if the culture helps an organization to adapt to external changes, it can lead to high performance in the long run. The fourth view is some organizations are relatively stable and fit with a relatively stable environment and risk-taking and innovation are not necessarily successful. Too much change can lead to instability, low cost-efficiency, risky projects, and a loss of sense of direction (Mousavi et al., 2015).

The literature revealed that the relationship between organizational culture and organizational performance is presented in different ways, some researchers tried to relate organizational performance directly with an organizational culture that, if there is a strong organizational culture there will be better organizational performance. In other instances, it is revealed that organizational performance is strongly linked with employee's performance and behaviour and even with the type and size of the organization. Thus, employee performance is one aspect of a company that is of great concern to company managers. Because the success of a company is very dependent on the performance of its employees. Employee performance is something that affects how much it contributes to a company. The performance reflects how well employees meet the standards of a job. Motivate employees to work, develop individual abilities, in the future, employees can provide feedback on performance in the self-development process. Employee performance is a process and the result of individual and group performance that can be accounted for both in terms of quality, quantity, and timeliness in completing work according to the abilities and talents of employees (Rohman et al., 2021). 


\section{Knowledge Management in Organizational Culture, and Performance}

There is yet a gap in explorative research that seeks to give cognizance to a typological scaling of organizational knowledge and how firms apply their dimensions to enhance performance in developing economies. In strategic management and human resource development literature, authors have attempted to explain the possible relationship between organizational knowledge and firm performance (Ibidunni,2020). The most significant gap in the literature is the lack of large-scale empirical evidence that KM makes a difference to organizational performance (Zack et al.,2009). Organizational knowledge incorporates organizational dynamic capabilities in a way that potentially submerges the firm's internal and external contexts to jointly enhance organizational performance (Ibidunni,2020). Four key dimensions of KM practice were identified from the literature that appears to relate to organizational performance, the ability to locate and share existing knowledge; the ability to experiment and create new knowledge; a culture that encourages knowledge creation and sharing; and a respect for the strategic value of knowledge and learning (Zack et al., 2009).

Having the knowledge of effective organizational culture in the corporate group is important to improve performance. Knowledge of organizational culture is crucial for business managers because an organizational culture has the potential to impact productivity and performance in the organization (Tedla,2016). For practising knowledge managers, the key point is that to be simply engaged in various KM practices is not expected to have a significant impact on organizational performance. Value from the investment in knowledge management will be realized when the organization achieves high capability in the performance of those KM practices, and the greatest level of organizational performance is expected from those firms who significantly engage in all of the KM practices (Zack et al., 2009).

\section{Discussion and Conclusion}

\section{Discussion}

This literature review has assessed the relationship between organizational culture and organizational performance. It also tried to review different theoretical organizational models developed by organizational culture researchers and discussed the relationship between organizational culture and organizational performance.

The review showed that organizations with a strong culture that motivates their employees to show better performances in their business operation than the organizations that give little attention to their organizational culture. Moreover, the review indicated that further research is needed as to whether organizational performance is influenced more by an organization having a strong culture or not.

The construction industry in developing countries plays a significant role in economic growth and development. However, there is a severe knowledge gap to link organizational culture, organizational performance, and knowledge management together in the construction industry environment to enhance the sector to contribute to the expected level, and further study is needed to provide detailed policy implications in the next phase of this study.

The review suggested that the unique organizational characteristics of construction industry project management are influenced by organizational culture, which in turn influences the performance components in the industries. The study also assessed the relationship between 
organizational culture, organizational performance, and the importance of knowledge management framework in the organizational culture of the construction industry.

The Competing values framework developed by Cameron and Quinn (2006) is discussed as an appropriate model to implement in the construction industry organizational culture environment.

\section{Conclusion}

From the literature review, it is revealed that there is no universally agreed definition of organizational culture and organizational performance. It can be seen from the literature that there is a positive correlation between organizational culture and organizational performance.

The literature shows that there is a severe shortage of literature regarding construction industry organizational culture in developing countries. It is necessary to consider construction from the perspective of its unique characteristics of organizational culture to measure organizational performance, especially in a developing country context.

The models developed by Cameron and, Quinn (2006) is considered a relevant model in the construction organizational environment, and further research is needed to present a detailed analysis in this regard.

\section{References}

Albayrak, G., \& Albayrak, U. (2014). Organizational Culture Approach and Effects on Turkish Construction Sector. APCBEE Procedia, 9, 252-257. https://doi.org/10.1016/j.apcbee.2014.01.045

Alla, M. Y. O., \& Hassan, A. S. (2017). Organization Culture Impact on Sudanese Construction Project performance. 18, 12.

Arditi, D., Nayak, S., \& Damci, A. (2017). Effect of organizational culture on delay in construction. International Journal of Project Management, 35(2), 136-147. https://doi.org/10.1016/j.ijproman.2016.10.018

Botez, C., \& Coteț, G. B. (2020). THE CORPORATE MANAGEMENT MODEL FROM THE PERSPECTIVE OF ORGANIZATIONAL CULTURE. 15, 10.

Cameron, K. S., \& Quinn, R. E. (2006). Diagnosing and changing organizational culture: Based on the competing values framework (Rev. ed). San Francisco, Calif: Jossey-Bass.

Dakhil, A. (n.d.). THE CONTRIBUTION OF THE CONSTRUCTION INDUSTRY TO ECONOMIC DEVELOPMENT IN LIBYA. 193.

Ehtesham, U. M., Muhammad, T. M., \& Muhammad, S. A. (n.d.). Relationship between Organizational Culture and Performance Management Practices: A Case of University in Pakistan. Journal of Competitiveness, (4), 9.

https://www.mindtools.com/pages/article/newSTR_86.htm

Huey Yiing, L., \& Zaman Bin Ahmad, K. (2009). The moderating effects of organizational culture on the relationships between leadership behavior and organizational commitment and between organizational commitment and job satisfaction and performance. Leadership \& Organization Development Journal, 30(1), 53-86. https://doi.org/10.1108/01437730910927106

Ibidunni, A. S. (2020). Exploring knowledge dimensions for improving performance in organizations. Journal of Workplace Learning, 32(1), 76-93. https://doi.org/10.1108/JWL-01-2019-0013

Jenatabadi, H. S. (2015). An Overview of Organizational Performance Index: Definitions and Measurements. SSRN Electronic Journal. https://doi.org/10.2139/ssrn.2599439

Joseph E. Champoux-Organizational Behavior_Integrating Individuals, Groups, and Organizations-Routledge (2016).pdf. (n.d.).

Kinoshita, K. (2014). Possibility of predicting neurological outcome using regional cerebral oxygen saturation (rSO2) after cardiac arrest. Resuscitation, 85(9), e133. https://doi.org/10.1016/j.resuscitation.2014.04.031

Larentis, F., Antonello, C. S., \& Slongo, L. A. (2019). Inter-Organizational Culture: Linking Relationship Marketing with Organizational Behavior. Cham: Springer International Publishing. https://doi.org/10.1007/978-3-030-00392-0

Leithy, W. E. (2017). Organizational Culture and Organizational Performance. International Journal of Economics \& Management Sciences, 06(04). https://doi.org/10.4172/2162-6359.1000442 
Matkó, A., \& Takács, T. (2017). Examination of the relationship between organizational culture and performance. International Review of Applied Sciences and Engineering, 8(1), 99-105. https://doi.org/10.1556/1848.2017.8.1.14

Morcos, M. (n.d.). ORGANISATIONAL CULTURE: DEfINITION AND TRENDS. ORGANISATIONAL CULTURE, 9.

Mousavi, S. A., Hosseini, S. Y., \& Hassanpour, N. (2015). State Bank Br2a3n4c5h-3e7s45. 8(1), 20.

Nifa, F. A. A., \& Ahmed, V. (n.d.). THE ROLE OF ORGANIZATIONAL CULTURE IN CONSTRUCTION PARTNERING TO PRODUCE INNOVATION. 11.

Ofori, G. (n.d.). Nature of the Construction Industry, Its Needs and Its Development: A Review of Four Decades of Research. 21.

Oney-Yazic, E., Arditi, D., \& Uwakweh, B. O. (n.d.). ORGANIZATIONAL CULTURE IN U.S. CONSTRUCTION COMPANIES. 10.

Prajogo, D. I., \& McDermott, C. M. (2011). The relationship between multidimensional organizational culture and performance. International Journal of Operations \& Production Management, 31(7), 712-735. https://doi.org/10.1108/01443571111144823

Rohman, A. F., Indiyati, D., \& Ghina, A. (2021). The Influence of Organizational Culture and Employee Engagement on Employees Performance at Telkom University, Indonesia. 3(1), 14.

Šandrk Nukić, I. (2018). Organizational Culture as a Determinant of Construction Companies’ Competitiveness: Case Study of Croatia. In J. Vveinhardt (Ed.), Organizational Culture. IntechOpen. https://doi.org/10.5772/intechopen.77165

Škerlavaj, M., Štemberger, M. I., Škrinjar, R., \& Dimovski, V. (2007). Organizational learning culture-The missing link between business process change and organizational performance. International Journal of Production Economics, 106(2), 346-367. https://doi.org/10.1016/j.ijpe.2006.07.009

Tedla, T. B. (n.d.). The Impact of Organizational Culture on Corporate Performance. 157.

Teräväinen, V. J., Junnonen, J.-M., \& Ali-Löytty, S. (2018). Organizational Culture: Case of the Finnish Construction Industry. Construction Economics and Building, 18(1), $48-69$. https://doi.org/10.5130/AJCEB.v18i1.5770

Yahyagil, M. Y. (n.d.). The interdependence between the concepts of organizational culture and organizational climate: An empirical investigation. 30.

Yildiz, E. (2014). A Study on the Relationship between Organizational Culture and Organizational Performance and a Model Suggestion. International Journal of Research in Business and Social Science (2147-4478), 3(4), 52-67. https://doi.org/10.20525/ijrbs.v3i4.117

Zack, M., McKeen, J., \& Singh, S. (2009). Knowledge management and organizational performance: An exploratory analysis. Journal of Knowledge Management, 13(6), 392-409. https://doi.org/10.1108/13673270910997088 